\title{
Global initiative for chronic obstructive lung diseases (GOLD): time to act
}

\author{
R. Pauwels
}

\section{What is global initiative for chronic obstructive lung diseases?}

In January 1997, chronic obstructive pulmonary disease (COPD) experts from several countries met in Brussels, Belgium to explore the development of a Global Initiative for Chronic Obstructive Lung Disease (GOLD). Representatives of the National Heart, Lung and Blood Institute, USA (NHLBI) and of the World Health Organization (WHO) attended. Participants agreed that the project was timely and important, and recommended the establishment of a panel with expertize on a wide variety of COPDrelated topics to prepare an evidence-based document on diagnosis, management, and prevention of COPD as a tool for GOLD. From 1998-2000, the panel members met several times to prepare the document (see further). In 2001, the GOLD initiative was firmly launched in collaboration with NHLBI and WHO. The project was, and continues to be, supported by unrestricted educational grants from a multitude of pharmaceutical companies.

The goals of GOLD are to increase awareness of COPD and decrease morbidity and mortality from this disease. GOLD aims to improve prevention and management of COPD through a concerted worldwide effort of people involved in all facets of healthcare and healthcare policy, and to encourage a renewed research interest in this extremely prevalent disease.

\section{Why global initiative for chronic obstructive lung diseases?}

COPD is a major cause of chronic morbidity and mortality throughout the world [1]. COPD is currently the fourth leading cause of death in the world [2], and further increases in the prevalence and mortality of the disease can be predicted in the coming decades. In 1990, COPD ranked twelfth as cause of disabilityadjusted life years (DALYs) lost worldwide [3-6]. DALY is the sum of the life years lost to premature death and to disability. This measure reflects the burden of a disease on the society. It is predicted that

Dept of Respiratory Diseases, University Hospital, Ghent, Belgium.

Correspondence: R. Pauwels, Dept of Respiratory Diseases, University Hospital, De Pintelaan 185, B9000, Ghent, Belgium. Fax: 3292402341 by 2020 COPD will be the third leading cause of death and the fifth leading cause of lost DALYs worldwide. As a community of people who care for and are interested in respiratory diseases, it is time that a major effort is focused on this disease. A nihilistic attitude toward COPD has arisen among some healthcare providers, due to the relatively limited success of primary and secondary prevention (i.e. avoidance of factors that cause COPD or its progression), the prevailing notion that COPD is largely a self-inflicted disease, and disappointment with available treatment options. The same arguments could be used for many other highly prevalent diseases, including the major cardiovascular diseases. This has, however, not precluded great basic and clinical research efforts and successful prevention campaigns for these diseases.

\section{Global initiative for chronic obstructive lung disease documents}

One strategy to help achieve GOLD's objectives is to provide healthcare workers, healthcare authorities, and the general public with state-of-the-art information about COPD and specific recommendations on the most appropriate management and prevention strategies. The GOLD workshop report, Global Strategy for the Diagnosis, Management, and Prevention of COPD, is based on the best-validated current concepts of COPD pathogenesis and the available evidence on the most appropriate management and prevention strategies [1]. An expert panel has developed the GOLD workshop report. NHLBI and WHO staff, in concert with the original group, identified individuals from many regions of the world to serve on the expert panel, which included health professionals in the areas of respiratory medicine, epidemiology, pathology, socioeconomics, public health, and health education.

The process was initiated by a review of all existing COPD guidelines and an extensive review of the literature on the issues that showed disagreement between these guidelines. During the writing of the draft form of the document, further literature searches were performed. The draft conclusions were presented at a European Respiratory Society (ERS) and an American Thoracic Society (ATS) symposium for an open peer discussion. The final draft was then sent around for comments to individual COPD experts and to the major respiratory societies. The final GOLD workshop report incorporates many of their 
comments, and thus, provides state-of-the-art information about COPD for pulmonary specialists and other interested physicians. The document includes levels of evidence for the various management recommendations.

The workshop report has also been used as the basis for the development of more concise and practical documents. An executive summary has been published in the American Journal of Respiratory and Critical Care Medicine and as a National Institute of Health (NIH) publication [7, 8]. A "Pocket Guide to COPD Diagnosis, Management and Prevention, a guide for physicians and nurses" is available as a NIH publication [9]. A small guide for patients and their families is currently in development. All documents can be obtained from the GOLD Secretariat located at the Dept of Respiratory Diseases, University Hospital, De Pintelaan 185, B9000 Ghent, Belgium.

All documents as well as a slide kit are available and can be downloaded from the GOLD website [10].

\section{Where do we go from here and what can you do about it?}

Writing and publishing guidelines is a futile effort if not implemented. A major task is improving the early diagnosis, management and prevention of COPD. It is encouraging to note that many international and national respiratory societies (ATS, American College of Chest Physicians, Asian Pacific Society of Respirology, Latin American Thoracic Society, ERS) have decided to endorse the GOLD project. Many societies and individuals (GOLD launch leaders) have committed themselves to the implementation of GOLD. Their names can be found on the GOLD website.

Everyone is invited to actively participate in their national programmes or even to start one, if there is not yet one up and running. As a society and community of respiratory physicians, chronic obstructive pulmonary disease must be taken on as a major health problem.

\section{References}

1. Global Initiative for Chronic Obstructive Lung Disease. Global Strategy for the Diagnosis, Management and Prevention of Chronic Obstructive Pulmonary Disease. NHLBI/WHO workshop report. Bethesda, National Heart, Lung and Blood Institute, 2001; NIH Publication No 2701: 1-100.

2. World Health Organization. World Health Report 2000. Geneva, World Health Organization, 2000.

3. Murray CJ, Lopez AD. Mortality by cause for eight regions of the world: Global Burden of Disease Study. Lancet 1997; 349: 1269-1276.

4. Murray CJ, Lopez AD. Alternative projections of mortality and disability by cause 1990-2020: Global Burden of Disease Study. Lancet 1997; 349: 14981504.

5. Murray CJ, Lopez AD. Global mortality, disability, and the contribution of risk factors: Global Burden of Disease Study. Lancet 1997; 349: 1436-1442.

6. Murray CJ, Lopez AD. Regional patterns of disability-free life expectancy and disability-adjusted life expectancy: global Burden of Disease Study. Lancet 1997; 349: 1347-1352.

7. Global Initiative for Chronic Obstructive Lung Disease. Executive Summary: Global Strategy for the diagnosis, management and prevention of Chronic Obstructive Pulmonary Disease. Bethesda, National Heart, Lung and Blood Institute, National Institutes of Health, 2001; NIH Publication No 2701A: 1-30.

8. Pauwels RA, Buist AS, Calverley PM, Jenkins CR, Hurd SS. Global strategy for the diagnosis, management, and prevention of chronic obstructive pulmonary disease. NHLBI/WHO Global Initiative for Chronic Obstructive Lung Disease (GOLD) Workshop summary. Am J Respir Crit Care Med 2001; 163 : 1256-1276.

9. Global Initiative for Chronic Obstructive Lung Disease. Pocket Guide to COPD diagnosis, management and prevention. A guide for physicians and nurses. Bethesda: National Heart, Lung and Blood Institute, National Institutes of Health, 2001. NIH Publication No 2701B: 1-23.

10. http://www.goldcopd.com. 